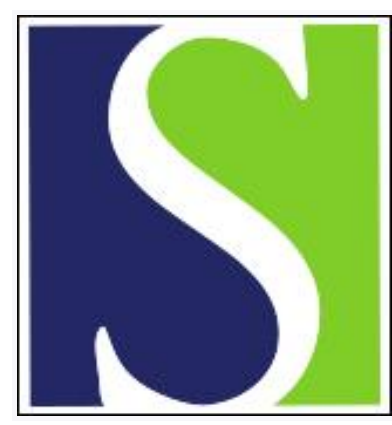

Scand J Work Environ Health 1995;21(1):3-14

https://doi.org/10.5271/sjweh.2

Issue date: Feb 1995

\title{
Occupational back pain -- an unhelpful polemic
}

by Frank JW, Pulcins IR, Kerr MS, Shannon HS, Stansfeld SA

The following articles refer to this text: 2001;27(5):346-352;

2011;37(2):99-108

Key terms: biomechanics; epidemiology; etiology; methodology; psychosocial risk factor; review; risk factor; work-related back pain; workers' compensation

This article in PubMed: www.ncbi.nlm.nih.gov/pubmed/7784861

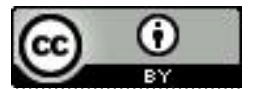




\title{
Occupational back pain - an unhelpful polemic
}

\author{
by John W Frank, MD, ${ }^{1,2,3}$ Indra R Pulcins, MA, ${ }^{1,2}$ Mickey S Kerr, MSc, ${ }^{1,2}$ Harry S Shannon, PhD, ${ }^{1,4}$ \\ Stephen A Stansfeld, PhD ${ }^{1,5}$
}

\begin{abstract}
Frank JW, Pulcins IR, Kerr MS, Shannon HS, Stansfeld SA. Occupational back pain - an unhelpful polemic. Scand J Work Environ Health 1995;21:3-14.

In most industrialized countries, disability and work absence due to occupational back pain have risen steadily in recent decades. Conventional views of the causes of this slow epidemic tend to fall into one of the following three areas: (i) the clinical pathology view, which attributes the level of pain and disability to either the severity of the initial injury or to psychosomatic conditions; (ii) the biomechanical exposures view, which attributes the problem to hazardous and preventable conditions of work; and (iii) the perverse incentives view, which suggests that reporting and disability are influenced by a combination of work dissatisfaction and accessible disability benefits. This paper reviews, from an epidemiologic perspective, the specific methodological hurdles faced during investigations of the etiology of occupational back pain. It is argued that methodological issues have contributed to the perpetuation of the three distinct but incomplete views of the problem. New research directions are suggested and a broader interdisciplinary perspective is proposed to help resolve the existing polemic.
\end{abstract}

Key terms biomechanics, epidemiology, etiology, methodology, psychosocial, review, risk factors, workers compensation, work-related.

Researchers and policy makers in occupational health frequently encounter contradictory evidence concerning the causes of work-related ill health. The debate over occupational back pain brings together, however, a particularly diverse range of views among labor groups, corporate interests, insurers, and other third-party payers, as well as a wide spectrum of health professionals. In the resulting encounter between these various perspectives, the genuine complexity of the "industrial back" may be neglected in favor of primary attribution to either worker or workplace factors.

This paper explores conventional views of occupational back pain. We contend that much of the research on the causes of occupational back pain has not yet bridged narrow disciplinary vantage points. We argue for the need for transdisciplinary research to meet the methodological challenges presented by occupational back pain. In the process, we hope to shed light on one of the industrialized world's most common causes of chronic disability before middle age (1).
In the following sections, we briefly review what is known about the burden of illness attributed to occupational back pain. We then present three contrasting views of the etiology and prognosis of occupational back pain, followed by a discussion of how narrow adherence to these perspectives may have contributed to the methodological problems evident in the published literature on occupational back pain. Finally, we propose future research directions that could help resolve the present backpain polemic.

\section{Burden of illness}

Several studies have shown that $60-80 \%$ of the general population is afflicted with disabling low-back pain at some point in life $(2-4)$. The largest single category of lost-time workers' compensation claims in most jurisdictions is nonspecific disorders of the lower spine

1 Institute for Work \& Health, Toronto, Ontario, Canada.

2 Department of Preventive Medicine and Biostatistics, Graduate Department of Community Health, University of Toronto, Toronto, Ontario, Canada.

3 Population Health Program, Canadian Institute for Advanced Research, Canada.

4 Department of Clinical Epidemiology and Biostatistics, McMaster University, Hamilton, Ontario, Canada.

5 Department of Psychiatry, University College London Medical School, London, United Kingdom.

Reprint requests to: Dr J Frank, Institute for Work \& Health, Suite 702, 250 Bloor St, E, Toronto, Ontario, Canada M4W 1E6. 
- often called mechanical low-back pain (5). Typically, some 80 to $90 \%$ of back pain claimants return to work (or at least cease receiving benefits) within one to two months after their claim begins. The "recovery curve" of this condition, depicted as the distribution of time spent receiving compensation benefits from the Ontario Workers' Compensation Board during 1991, is presented in figure 1. Although they account for the bulk of all costs related to back claims, people who become chronically disabled represent only about 5 to $10 \%$ of compensation claimants for back pain (5). A significant additional minority, while not proceeding directly to chronic disability, suffers from multiple recurrences that can be progressively severe and prolonged $(6,7)$. Few medical conditions share such a diverse clinical picture: acute onset with prompt, full recovery in the majority; unpredictable recurrences or prolonged suffering in some; and permanent disability in the small minority. Depression is one of the few common illnesses which shows a similar course spectrum (8).

Workers' compensation claims for back pain have been steadily increasing in recent years in terms of frequency and global cost, even after demographic changes are accounted for $(4,9)$. Moreover, Waddell has also shown a sixfold increase in lost time from back pain since the mid-1950s in the United Kingdom according to the system of general sickness benefits, which does not require work attribution (10). Thus there appears to

\section{Duration of Paid Disability for Low Back Strain: Ontario WCB Lost Time Claims 1991}

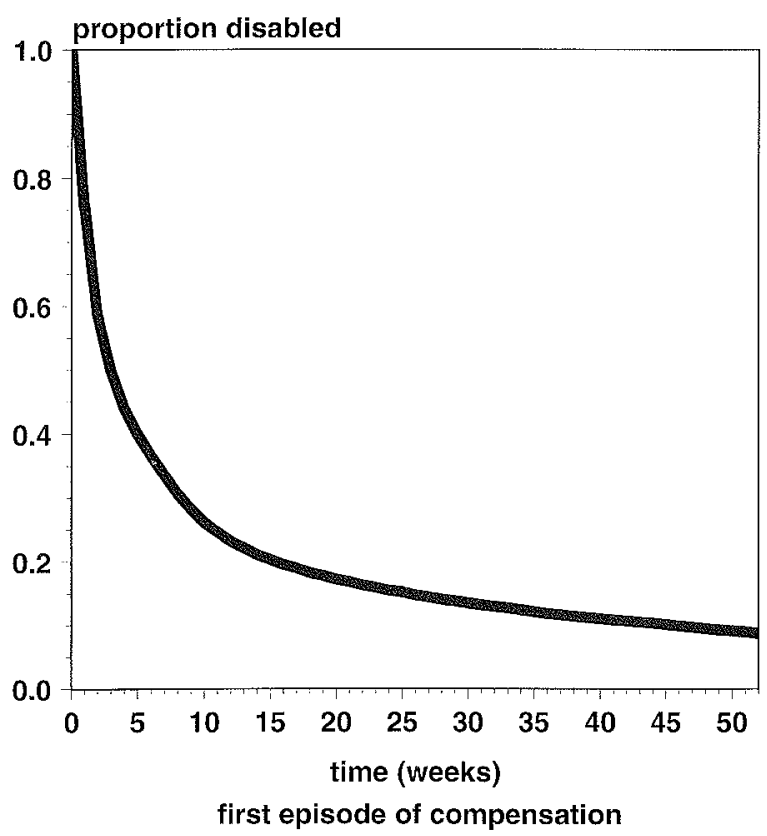

Figure 1. Recovery curve (duration of disability benefits) for occupational back pain. have been limited success either in identifying the causes of back pain (or disability or both) or, more importantly, in translating this knowledge into effective intervention in the workplace or in the general population $(11,12)$.

\section{Three current views of occupational back pain}

As shown in figure 2, there are three prevailing schools of thought influencing research on the etiology and prognosis of occupational back pain. They can be outlined in more detail as follows:

1. The clinical pathology view focuses on the pathology and prognosis of the worker, rather than on etiology or prevention. Most occupational strains and sprains are attributed to subtle damage to soft tissues, which should normally heal within a few weeks of symptom onset. Disability is thought to arise from either of the following two mechanisms: inherently more severe injury (such as acute intervertebral disc herniation) (13) or clear secondary psychopathological complications (such as depression or a range of psychosomatic disorders historically labeled as "compensation neurosis") (14).

2. The biomechanical exposures view contends that the occurrence of occupational back injury, and its accompanying disability, is the result of adverse workplace biomechanical exposures that excessively or repetitively strain the tissues of the back. This view contends that pain and disability should be preventable either through intervention in workplace design to remedy the offending exposures (15-17) or through the type of legislation concerning workplace ergonomic exposures that is currently undergoing public consultation in North America $(18,19)$.

3. Conceptualizing causation more at the society level, the perverse incentives view maintains that back pain per se is a ubiquitous consequence of modern life $(20,21)$. The recent increases observed in reporting and disability are said to be rooted in a combination of dissatisfaction with work and the ready availability of workers' compensation and other disability insurance benefits. These "perverse incentives" are seen as promoting the initiation of claims and increasing the level and duration of disability associated with the claims $(11,20)$. While not necessarily implying that frank malingering is involved in either claims submission or prolongation, this view emphasizes the social context within which reporting and disability from back pain develops.

The back-pain perspective one subscribes to will undoubtedly influence the research approach one adopts, 


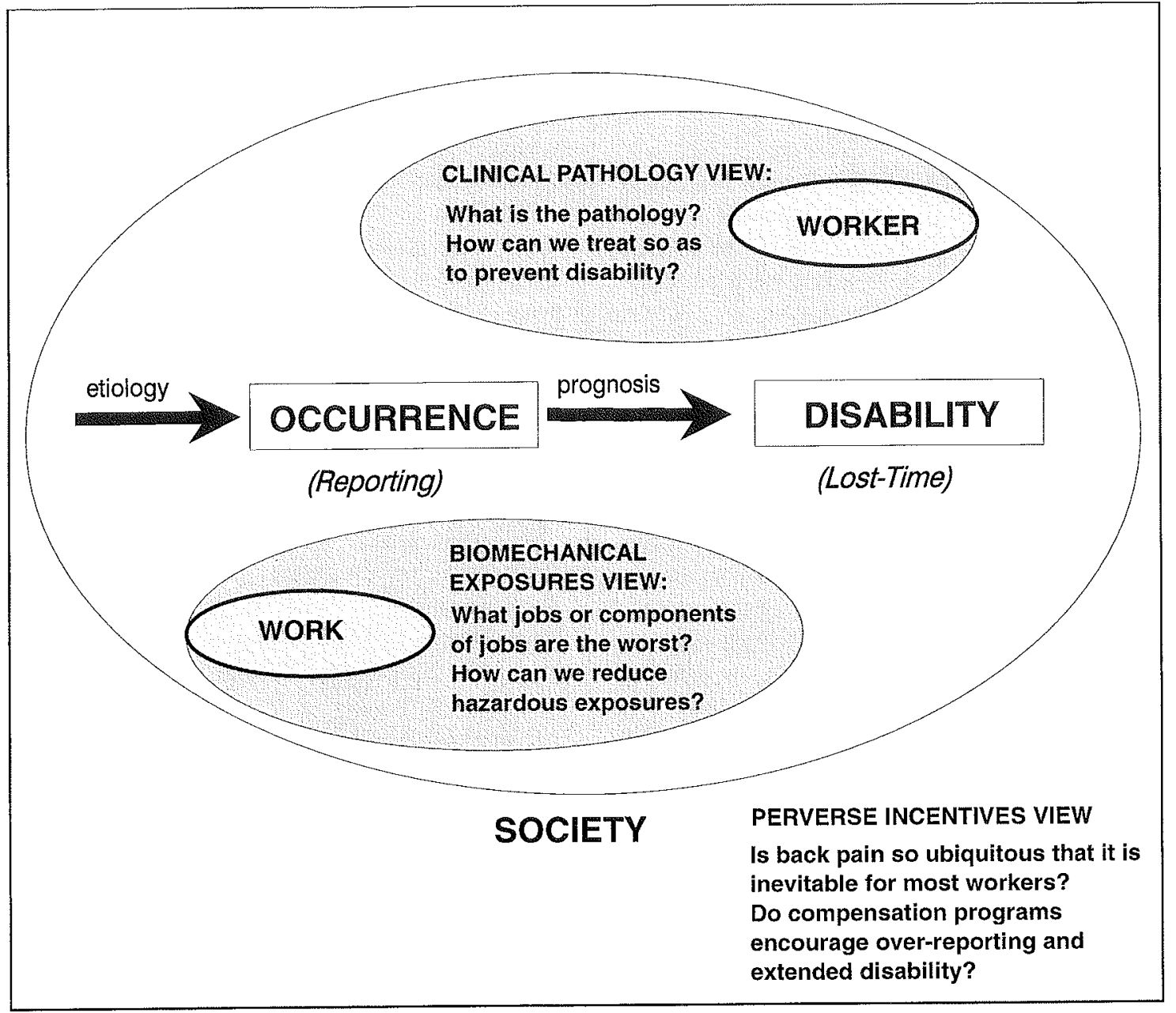

Figure 2. Three current views of occupational back pain.

especially in the selection of variables to be assessed. It is possible to find papers that have done a good job of addressing biomechanical factors (22), or psychological factors (23), or compensation factors (20), but few, if any, have given equal emphasis to factors from all three domains (24). In this paper we contend that disciplinary compartmentalization, and the methodological difficulties inherent in occupational back-pain research, have contributed to the formation of a subtle, but unhelpful polemic, most evident when the proponents of the different views are brought together. ${ }^{5}$ This polemic may be impeding our progress towards identifying and acting upon modifiable causes for occupational back pain and its related disability.

\section{Challenges to research}

Several thorough reviews of studies examining etiologic or prognostic risk factors for occupational and nonoccupational back pain have been published recently (11, 25-31). Research in these areas appears to be at a crossroads; even the best-designed investigations have explained only a small proportion of the total variance observed $(23,32-34)$. As argued by Waddell and others $(12,35,36)$, new conceptual models are needed if we are to advance our understanding of the etiology and prognosis of occupational back pain. Thus future studies will have to address the particular methodological and interdisciplinary challenges characteristic to investigations of

5 As witnessed by JWF during a heated panel discussion on the causes of the low-back pain "epidemic" at the Occupational Spinal Disorders: Primary, Secondary and Tertiary Care and Prevention Conference, Dallas, Texas, 1-3 October 1992. 
occupational back pain. Five of these challenges, outlined in figure 3 , are discussed in detail in this review.

\section{Defining "back pain"}

How a condition is defined will affect what a study finds, as well as how its results can be generalized. Occupational back pain has been defined differently in different studies; thus it is not surprising that there has been limited agreement on which factors are the most important in its etiology or prognosis. A case definition based on a specific pathology (such as herniated lumbar intervertebral disc) is the most relevant for the clinical pathology view. However, since so few cases have such demonstrable pathology, the findings from studies using specific clinical or pathological case definitions are of limited use in occupational settings $(5,37)$. A work-disability definition (such as lost-time status), more relevant to the biomechanical exposures and the perverse incentives view, also has problems associated with it. The reason for work absence can be affected by several factors, including (i) contextual problems such as delays in medical treatment or the absence of modified work or (ii) a range of psychosocial factors such as fear avoidance behavior $(38,39)$. One of the major limitations of etiologic studies of occupational back pain is that they are often restricted to examining only the cases that are reported to the workplace (often workers' compensation claims). Some people may choose to work with their pain rather than reporting it to the workplace or taking time off because of it. To study all symptomatic cases, investigators would be forced to survey repeatedly all members of the work force under study (to avoid subjects' failure to recall less severe episodes). However, a repeat-survey design in an occupational setting will uncover many previously unreported cases of pain (22). This hidden burden of illness can be viewed in one of two ways: (i) it is not central to the problem under study - that is, any back pain not

1. Defining back pain: what outcome/case definition is being studied?

2. Measuring back pain:

i) can it be validly and reliably measured?;

ii) how is severity determined?

3. Injury or disease: is it an acute event, a recurrent/chronic condition, or an industrial disease?

4. Distinguishing etiologic from prognostic risk factors: i) What are the limitations of cross-sectional data? ii) What is the best study design?

5. Assessing exposure:

i) How is an adequate range of exposure obtained?

ii) How comprehensive should the list of variables be?

Figure 3. Methodological issues in studying occupational back pain. causing lost time from work is merely a reflection of "normal life" in modern society - or (ii) inclusion of unreported, presumably less severe cases of disease or injury can provide a more complete spectrum of clinical severity to help one understand the etiology and prognosis of occupational back pain (40).

In either case, few employers will thank investigators for uncovering such a large burden of hidden (and potentially compensable) illness, let alone for intrusive repeated surveying of their work force. Thus it is not surprising that few published studies can claim to describe the risk factors for occupational back pain per se. Rather, most studies, including the landmark prospective cohort study of back pain on over 3000 employees at a Boeing airplane assembly plant $(23,32)$, have focused on risk factors for the reporting of back pain in the workplace. This approach may be appropriate if one is primarily interested in the disability arising from back pain, defined in terms of time lost from work. On the other hand, if one is interested in a broader etiologic picture of lowback pain, this definition may be inadequate. For example, the main findings of the Boeing study suggest that "dissatisfaction with work" is among the chief predictors of back pain reporting. These results need to be interpreted in light of the fact that many workers in a wide variety of settings have symptomatic episodes without reporting them to the employer or experiencing lost time, so their risk and prognostic factors may have gone unstudied. In a recent case-referent study of automobile assembly workers (22), approximately one-half of the reference population was excluded from the study because of recent unreported back pain. While the study consequently provided a sharp case-referent comparison for the effect of nonneutral trunk postures, its scope was limited since the case group represented only a subset of all those with symptoms.

\section{Measuring the severity of back pain}

\section{Can the severity of back pain be validly and reliably measured?}

Our inability to explain the causes and prognosis of back pain may be tied in part to our difficulty in diagnosing and measuring it. The lack of specificity and prognostic or therapeutic meaning attached to medical diagnoses for back pain is now widely accepted $(5,20,37,41,42)$. Less than $5 \%$ of working-age patients with back pain appear to have objectively demonstrable and specific pathological processes associated with their symptoms, even when computerized axial tomography (CAT) or magnetic resonance imaging (MRI) scans are obtained (42). Thus "mechanical back pain" has become a catchall diagnosis of exclusion for the vast majority of occupational cases. Further complicating back pain research, the 
training of primary care physicians stresses the importance of recognizing relatively rare, surgically remediable causes of back pain, such as herniated lumbar intervertebral disc, rather than dealing effectively with the garden-variety of back strain. Although very remote, the possibility of finding patients with herniated lumbar intervertebral disc among the case load of a primary care physician, combined with the common practice style of defensive medicine, drives many physicians to overinvestigate and overtreat a substantial fraction of their patients. Evidence documenting and questioning this aggressive pattern of medical practice is now accumulating from many sources $(4,20,43-45){ }^{6}$

Extraordinary research efforts and much funding have gone into attempts to identify a purely biomedical etiology for back pain and thereby minimize the influence of "nonorganic" psychological and social factors $(46,47)$. This approach has sometimes had an unfortunate undertone of insurance-fraud detection, especially when used to identify chronic pain patients who are said to have "functional overlay" as the underlying diagnosis. Indeed, an industry exists to identify high levels of test-retest variability in lifting and other tasks as evidence of nonorganic pain (48). Are patients with such variable test results fraudulent, psychologically unwell or just inconsistent? And, without a demonstrated "gold standard," are these tests providing data that may not be valid?

\section{How is the severity of back pain determined?}

Severity has the following two components of concern to researchers: (i) how to define it and (ii) how to measure it. In the context of workers' compensation, the term "severity" has traditionally been defined with respect to duration off work or time on compensation benefits, a seemingly circular notion. In a clinical setting, it is more difficult to define severity, because of the difficulty in establishing pathology (42). Beyond work status, investigators needing data on severity have had to rely on selfreported measures of pain, psychological status, and dysfunction, adapted from the social and psychological sciences, rather than traditional biomedical measures, such as laboratory or radiological measurements of altered structure or function. Apart from questionnaires assessing pain, pain-related behavior, and impaired function, very few measurement instruments have been shown to classify back-pain cases validly or to measure their "severity," at least in terms of predicting future risk of chronicity $(31,37,49,50)$. Yet, ironically, many workers' compensation systems forbid the use of patient-cen- tered measures of pain and disability, favoring instead traditional "objective" measures of impairment, which have not been shown to predict chronicity (51).

Evidence is now accumulating to suggest that a simplistic mind-body dichotomization of chronic pain is inappropriate. Ample clues are now available, from the pain literature $(52-55)$ and from the new field of psychoneuroendocrinology and immunology $(56,57)$, to suggest that patients with prolonged pain syndromes and other illnesses are not necessarily psychologically abnormal, although they may often be afflicted with depression and other co-morbidity (37). Newly identified feedback loops involving tissue inflammation, nociceptive sensory nerve stimulation, and central nervous system or endocrine amplification (58-62) have been identified in fibromyalgia patients. Chronic back-pain patients may be experiencing a similar, poorly understood vicious cycle of pain perpetuation, sometimes exacerbated by medical and social labeling of their problem as "psychogenic" (49, 63-67). Considering the complex natural history of chronic pain development in back-pain patients receiving compensation payments, the use of the simplistic and victim-blaming term "compensation neurosis" would now appear to be unjustified (66).

\section{Injury or disease?}

There is a wide spectrum of clinical profiles for occupational back pain, including people with acute pain attributed to a specific biomechanical exposure ("injury"?), and those experiencing frequent recurrences without any apparent exogenous cause ("disease"?). There are also widely varying administrative responses to this mix of etiologies in different jurisdictions (51). The claims submission process for workers' compensation systems frequently includes structured reporting forms requiring claimants to identify an exact date of onset and an explanation of how they were injured (68). Yet many claimants are unable to describe their condition according to the terms of this traditional injury model. Workplace case reports and compensation claim statistics based on this model thus inevitably tend to emphasize the acute traumatic aspects of occupational back pain. Since backpain claims with insidious onset or frequent recurrence of pain may be inaccurately portrayed, the usefulness of most routinely collected workers' compensation claims data on etiology is somewhat limited. A good example is the frequently used "cause" one sees on claim forms and accident reports of "overexertion," a term defying objec-

Indeed there is reason to believe that physicians in some American jurisdictions, caught up in legalistic defense of patients' rights, now routinely order CAT and MRI scans of uncomplicated early back pain "just in case." There is much anecdotal evidence to suggest that minor spinal and disc "defects," also routinely found in asymptomatic subjects of the same age, are then being overtreated in some centers by surgery, despite any firm epidemiologic evidence that it is warranted. 
tive definition. Investigators using such data without an adequate appreciation of these limitations run the risk of studying a socially (re)constructed version of events. It is perhaps therefore not surprising that so much uncertainty exists about whether occupational back pain should be treated as an acute injury, a repetitive injury, or an occupational disease. Interestingly, some labor movement publications are beginning to characterize it as a disease, albeit one with major ergonomic causes in some workplaces (69).

\section{Etiologic versus prognostic risk factors}

Studies of etiology properly focus on identifying factors associated with the onset of a condition. Prognosis studies, on the other hand, are concerned with identifying factors useful for the prediction of the future course of a disease, after it has begun. The distinction between etiologic and prognostic risk factors can often be blurred, especially for occupational back pain, for which medical, social, and political pressures contribute to the formation of disparate views of the problem. These views, discussed earlier, put different emphasis on etiology and prognosis, and different emphases can lead to apparent contradictions in study findings. Proponents of the biomechanical exposures view are more concerned with prevention; hence the focus is more on etiology than on prognosis. The clinical pathology view is focused more on treatment and impairment prognosis than on etiology or prevention, while the perverse incentives view is concerned chiefly with disability prognosis measured in days off work. (See figure 3.)

\section{Problem of cross-sectional studies}

Mechanical back pain reported at work has such a variable natural history that one must carefully differentiate risk factors affecting occurrence from those that adversely affect prognosis. Even though only a small minority of new cases has a duration lasting months or years, people with chronic pain form a relatively large proportion of any prevalent case population, since back pain is such a common and recurrent condition. The full incidence of such a ubiquitous complaint cannot generally be ascertained properly without a truly prospective study design that detects even short mild episodes, before they are over and forgotten. Episodes of short duration will tend to be underrepresented in any cross-sectional study (which, by definition, interviews subjects at only one point in time). This underrepresentation of short-lived and minor cases in such studies, due to "prevalenceincidence" bias, is made worse by the presence of "reporting or recall" and "volunteer" biases $(70,71)$. The result is that studies with designs that involve a mixture of prevalent and incident back-pain cases (72-77) cannot reliably distinguish between etiologic and prognostic risk factors. This confusion is particularly problematic for a condition like occupational back pain, for which several factors probably begin to influence outcome soon after onset (78). For example, does depression contribute to the onset of back pain, or is it a consequence of slower than expected resolution of the initial pain and disabilitycompensation process and thereby constitute a further impediment to recovery?

The biomechanical "heaviness" of the job, which affects the onset of symptoms and the ability to continue working, as well as the point at which one's normal work may be resumed, provides an additional example of the overlap between risk and prognostic factors for occupational back pain. A white-collar worker with back pain may be able to stay on the job or return to it soon after the onset of symptoms, unlike a blue-collar worker whose job requires the lifting of heavy loads $(79,80)$. Thus a cross-sectional study, with its overrepresentation of longterm cases, may exaggerate the effect of physical work load. Conversely, if a risk factor is generally protective against occurrence, but favors prolonged disability [such as older age, in some populations $(13,81)]$, a crosssectional study of both prevalent and incident cases will tend to underestimate the overall effect of that factor, because the opposing etiologic and prognostic effects will tend to cancel each other out.

\section{Need for appropriate study designs}

Ideally, one needs prospective ascertainment of incident cases of pain (or at least reported pain, if that is all that is feasible) to elucidate risk factors for occurrence. The identification of risk factors for adverse prognosis, on the other hand, requires the investigator to conduct internal comparisons within an inception cohort of cases (ie, cases that are all enrolled at a similar clinical stage of the condition) (82). This approach is all very challenging for studies in occupational settings, where many episodes are in fact midlife recurrences. Fortunately, a few studies which more clearly separate etiologic $(32,83,84)$ from prognostic $(85,86)$ risk factors have recently been published. Unfortunately little has been published that examined both sorts of risk factors within the same population to show how much a given factor (such as work heaviness or age) might influence both occurrence and prognosis. The prognostic factor analysis of the Boeing study is, however, forthcoming (Bigos, personal communication). At least two other combined etiologic and prognostic studies are in progress $(87,88)$.

\section{Assessing exposure}

\section{How comprehensive should the set of variables be?}

To limit bias and help avoid controversies regarding the interpretation of a study's findings, it is important to 
measure and control for all variables believed to be important risk factors or potential confounders for the condition being studied (82). When a narrow view of a condition's etiology or prognosis is adopted, important variables can be excluded from a study, and the amount of observed outcome variance that can be explained is therefore reduced. Risk factors examined in studies of occupational back pain have frequently been focused on one of the following two major domains: (i) work-related biomechanical factors or (ii) worker-related psychological factors. If the assessments of risk factors from both domains are not equally complete and accurate, the study's findings can be difficult to interpret.

For example, the results of the Boeing study $(23,32)$ linking "job dissatisfaction" with reported low-back pain, can be interpreted from two diametrically opposed and rather politicized perspectives: (i) the problem is with the worker or (ii) the problem is with the worlkplace. Dissatisfied workers can be viewed as manifesting their personal difficulties by filing reports of back pain, a ubiquitous symptom of modern existence. The Boeing results may also be interpreted in the context of the broader occupational and social milieu. According to the perverse incentives view, job dissatisfaction is dealt with by reliance on a generous and highly accessible compensation system. In both instances, it is the worker, not the work itself, who tends to be viewed as the main problem, although the latter view suggests the compensation "system" is as much at fault as the worker.

This interpretation contrasts sharply with that from the biomechanical exposures view, which emphasizes the links between the physical demands of work and back pain. The main findings of the Boeing study, in which job satisfaction was found to be associated with an increased risk of reporting back pain, seem to dispute the role of workplace biomechanical exposures in the etiology of occupational back pain. However, proponents of the biomechanical exposures view might argue that jobs with the highest levels of dissatisfaction were also the most physically demanding. Unfortunately, the extent of this interaction is difficult to assess from the Boeing study, because of its limited measurement of workplace biomechanical exposures. While psychosocial and psychological factors were assessed at the individual level, workplace biomechanical exposures were assessed at the group level only. These different measurement approaches may have led to increased misclassification error for the ergonomics variables. As discussed later in this paper, this measurement error differential could have made it more difficult to find an association between reported back pain and biomechanical exposures.

\section{How is an adequate range of exposure obtained?}

It is important to have measurements covering the full range of possible exposure for a given risk factor, espe- cially when investigating its role in conditions with multifactorial etiologies. To paraphrase Rothman, "If we all smoked, lung cancer would be thought of as a genetic [and perhaps nutritional] disease" (89). In other words, risk factors which vary the least in a given study population may be falsely interpreted as being unimportant in general, when otherwise excellent epidemiologic studies are conducted only within that specific population.

With a prospective cohort design, the Boeing study $(23,32)$ provides the most compelling empirical evidence to date for an association between psychosocial factors and the etiology of reported occupational back pain. However, for two separate reasons, the absence of any positive findings for biomechanical exposures does not mean that such exposures are unimportant: (i) the study workplace had a relatively narrow range of exposure for the biomechanical loading variables used (87) when there is little variation in exposure, the likelihood of a false negative finding (also called "beta" or "type II" error) is increased (90) - and (ii) the study used group measures for biomechanical exposures while psychosocial exposures were measured for each worker studied, thereby possibly biasing the biomechanical relative risk estimates towards the null (91). With only a few exceptions $(22,32,92)$, most studies have relied upon questionnaire data to estimate the physical demands of work, even though extensive validation exercises have shown the instruments used to date to yield inaccurate data $(91,93)$. Relative risks for exposure variables assessed with inaccurate measurement tools will tend to be systematically underestimated (89). Including inaccurately measured variables in a study may even bias the relative risk estimates for the other exposures being examined (94).

\section{Summary of methodological issues}

Given the combined insights gleaned from these various perspectives, it is unlikely that the modern epidemic of occupational back pain, which affects a wide variety of work forces in a wide range of jobs, can be attributed entirely to either problems with workers or problems with work. It seems more likely that the true picture lies somewhere in between. Yet when one looks for etiologic or prognostic studies that comprehensively assess biomechanical and psychosocial risk factors on all study subjects, one is disappointed. Most published work is dominated by sharp disciplinary boundaries that frame the different views of occupational back pain presented earlier. Typically, only one of the two categories of risk factors is well measured $(16,22,63,92,95-100)$. Few papers have attempted to disentangle the effects of various factors from both domains acting simultaneously. 
Apart from the expense and logistical difficulties resulting from the use of detailed individual and comprehensive exposure assessments, an additional problem may be the requirement of very large sample sizes to ensure adequate statistical power for detecting risk factor interactions (89). Fortunately, a new population-based study of low-back pain in Sweden (the MUSIC study) is explicitly designed with this problem in mind (88).

\section{Some suggested directions for research}

\section{Lessons from the epidemiology of chronic disease}

Recent validation of the importance of psychosocial and socioeconomic risk factors in the causation and prognosis of coronary heart disease $(101-104)$ lends useful insights into a more appropriate and less narrow conceptual model for occupational back pain. The need for a broader theoretical framework for modeling back pain at work, one that incorporates individual and workplace level measures of psychological, social, and physical factors contributing to disability, has already been pointed out by others $(11,12,36)$. Further research needs to assess prospectively the effects of both kinds of risk factors simultaneously or do controlled trials of specific preventive interventions.

The methodological standards used in epidemiologic studies of other chronic diseases need to be incorporated in studies on occupational back pain (82). First, there is a need to invest in large prospective studies, in preference to case-referent, ecological, and cross-sectional studies, to permit a clear separation of etiologic and prognostic risks. However, in view of the high cost and technical difficulty of direct biomechanical measures, case-referent studies will probably have to be used in the interim to develop inexpensive proxy measures of biomechanical exposures (eg, questionnaires) that capture these complex exposures with sufficient accuracy $(24,91,93)$. Second, there is a need for prognostic studies with multiple and repeated risk factor measurements early in the course of the condition. Biostatistical methods have been developed to handle such repeat measures $(105,106)$. Without adopting these standards, we are unlikely to understand the highly variable natural history of a condition which may have its prognosis determined to a large degree within a few weeks of onset by factors, such as reactions to continuing injury and pain, that are not all present at symptom onset (78).

\section{Lessons from the qualitative social sciences}

To get beyond narrow perspectives on occupational back pain, a more interdisciplinary research approach is needed, such as one which integrates qualitative social science methods with the quantitative approach of epidemiology (107, 108). Qualitative research methods can yield crucial insights into the personal meaning attached to the social, psychological, and economic aspects of multifactorial illness such as occupational back pain (109, 110). Qualitative investigations are a rich source of contextual information that can be used to generate new hypotheses and develop new questionnaires for epidemiologic studies collecting quantitative data on a large scale, and to guide the multivariate analysis of how chronic disability develops $(111,112)$. Without the insights provided by preliminary qualitative work, there is little hope of appropriately modeling the development of ill health when large numbers of social and psychological variables are used that are frequently collinear, as in the case of occupational back pain.

\section{The bigger picture (a population health perspective)}

Any research on why persons become work-disabled, whether from back pain or from other causes, must take into account current overall trends in disability in our society. Data from periodic health surveys suggest that, since about the middle of this century, consecutive generations in the population of the United States may have become successively more disabled, as assessed from self-reports (113). It is unclear whether this situation can be attributed to improved survival (medical salvage) of the chronically ill, to lowered cultural thresholds for defining disability, or to real increases in disability incidence. Major social and economic adjustments may be necessary in our approach to disability. It will not be sufficient to simply let those with physical, mental, or emotional health problems - of any cause - be channeled into less satisfying work or unemployment. Neither will it be the best course of action for such persons to be simply paid a disability pension, when many of them would rather work. Recent regulatory changes in the United States, involving the Americans with Disabilities Act, may have already necessitated such new courses of action.

A broader "population health" perspective is warranted, as advocated by the Program in Population Health of the Canadian Institute of Advanced Research (CIAR) $(107,108)$. This program has provided a generalized conceptual framework for thinking about the many reasons why some individuals or groups are healthier than others, with important implications for health policy. It also presents several general themes illustrated throughout this paper. In particular, a population health framework. necessitates the formation of strong transdiscipli- 
nary linkages among researchers in the biological, clinical, social, and community health sciences to understand better which public health and clinical policy levers are best suited to particular population health problems (114).

\section{Concluding remarks}

Through much of history, science has often found itself locked into narrow cognitive paradigms, reflecting the views of the society around it $(115,116)$. In the case of occupational back pain, prevailing notions of causation, rooted largely in either the "worker" or the "work," have frequently resulted in narrow unidisciplinary investigations of the problem. Thus much of the existing literature is limited by its tendency to shore up one or the other viewpoint in an unbalanced way. There is a need for more broadly based investigations in the future and for more rigorous critiques of the evidence to date. The epidemiologic criteria for establishing causation are much more demanding than the evidence that one study in one setting can provide (82). There is much scope, both methodologically and substantively, for innovative approaches to our understanding of occupational back problems. The key to this understanding, however, lies outside of the traditional boundaries of the biomedical model, in the realm of truly transdisciplinary research with a population health perspective. These boundaries need to be crossed if we are to generate further useful evidence from research and transform the present unhelpful back pain polemic into a vehicle for understanding and effective intervention.

\section{Acknowledgments}

This study was supported in part by a national health fellowship to MS Kerr and IR Pulcins from the National Health Research and Development Program (NHRDP), Canada, and a fellowship to JW Frank with the Canadian Institute for Advanced Research.

\section{References}

1. Lawrence VA, Tugwell P, Gafni A, Kosuwon W, Spitzer WO. Acute low back pain and economics of therapy: the iterative loop approach. J Clin Epidemiol 1992;45(3):30111.

2. Biering-Sorensen F. A prospective study of low back pain in a general population: I occurrence, recurrence and aetiology. Scand J Rehabil Med 1983;15:71-9.

3. Deyo RA, Cherkin D, Conrad D, Volinn E. Cost, controver- sy, crisis: low back pain and the health of the public. Annu Rev Public Health 1991;12:141-56.

4. Kelsey JL, Hochberg MC. Epidemiology of chronic musculoskeletal disorders. Annu Rev Public Health 1988;9:379_401.

5. Spitzer WO, LeBlanc FE, Dupuis M, Abenheim L, Belanger AY, Bloch R, et al. Scientific approach to the assessment and management of activity-related spinal disorders: a monograph for clinicians: report of the Quebec task force on spinal disorders. Spine 1987;12(7S):S4 55.

6. Rossignol M, Suissa S, Abenhaim L. The evolution of compensated occupational spinal injuries - a three year followup study. Spine 1992;17(9): 1043-7.

7. Von Korff M, Deyo RA, Cherkin D, Barlow W. Back pain in primary care - outcomes at 1 year. Spine 1993;18(7):85562.

8. Jablensky A. Prediction of the course and outcome of depression. Psychol Med 1987;17:1-9.

9. Nachemson AL. Spinal disorders: overall impact on society and the need for orthopedic resources. Acta Orthop Scand 1991;62 suppl 241:17-22.

10. Waddell G. Simple low back pain: rest or active exercise. Ann Rheum Dis 1993;52:317-9.

11. Battie MC, Bigos SJ. Industrial back pain complaints: a broader perspective. Orthop Clin North Am 1991;22(2): $273-82$.

12. Battie MC. Minimizing the impact of back pain: workplace strategies. Semin Spine Surg 1992;4(1):20-8.

13. Rossignol M, Lortie M, Ledoux F. Comparison of spinal health indicators in predicting spinal status in a 1 year longitudinal study. Spine 1993;18(1):54-60.

14. Reilly PA, Travers R, Littlejohn GO. Epidemiology of soft tissue rheumatism: the influence of the law. J Rheumatol $1991 ; 18(10): 1448-9$

15. Chaffin DB, Park KS. A longitudinal study of low-back pain as associated with occupational weight lifting factors. Am Ind Hyg Assoc J 1973;34:513-25.

16. Herrin GD, Jaraiedi M, Anderson CK. Prediction of overexertion injuries using biomechanical and psychophysical models. Am Ind Hyg Assoc J 1986;47(16):322-30.

17. National Institute for Occupational Safety and Health (NIOSH). Work practices guide for manual lifting. Washington, DC: NIOSH, 1981.

18. Haag $\mathrm{AB}$. Ergonomic standards, guidelines, and strategies for prevention of back injury. Occup Med 1992;7(1):15565.

19. Worker's Compensation Board of British Columbia (WCBBC). Draft ergonomic regulations and: statement of context; draft code of practice; proposed implementation strategy. Vancouver, BC: WCBBC, 1994.

20. Nachemson AL. Newest knowledge of low back pain: a critical look. Clin Orthop Rel Res 1992;279:8-20.

21. Waddell G. Low back disability: a syndrome of Western civilization. Neurosurg Clin North Am 1991;2:719-38.

22. Punnett L, Fine LJ, Keyserling WM, Herrin GD, Chaffin DB. Back disorders and non-neutral trunk postures of automobile assembly workers. Scand J Work Environ Health 1991;17:337-46.

23. Bigos SJ, Battie MC, Spengler DM, Fisher LD, Fordyce WE, Hansson T, et al. A prospective study of work perceptions and psychosocial factors affecting the report of back injury. Spine 1991;16(1):1-6.

24. Kerr MS, Shannon HS, Frank JW. A critical review of the epidemiologic evidence linking workplace ergonomic fac- 
tors and occupational low-back pain [abstract]. In: International Epidemiological Association. New pathways in epidemiology: program. Sydney: International Epidemiological Association, 1993;47.

25. Anderson JAD. Low-back pain - cause and prevention of long-term handicap (a critical review). Int Rehabil Med 1981;3(2):89-93.

26. Deyo RA. Low-back pain. Adv Pain Res Therap 1991; 18:291-303.

27. Frymoyer JW, Cats-Baril WL. An overview of the incidences and costs of low back pain. Orthop Clin North Am 1991;22(2):263-71.

28. Polatin PB. Precictors of low back pain disability. In: White AH, Anderson R, editors. Conservative care of low back pain. Baltimore, MD: William and Wilkins 1991:265-73.

29. Cats-Baril W, Frymoyer JW. Demographic factors associated with the prevalence of disability in the general population. Spine 1991;16(6):671-4.

30. Bongers PM, de Winter CR, Kompier MAJ, Hildebrandt VH. Psychosocial factors at work and musculoskeletal disease. Scand J Work Environ Health 1993;19:297-312.

31. Pulcins IR, Goel V, Cohen JE, Frank JW. A structured critical review of acute back pain prognosis studies. Toronto: Institute for Work and Health, 1994. Working paper no 21.

32. Bigos SJ, Battie MC, Spengler DM, Fisher LD, Fordyce WE, Hansson T, et al. A longitudinal, prospective study of industrial back injury reporting. Clin Orthop Rel Res 1992;279: $21-34$.

33. Cats-Baril WL, Frymoyer JW. Identifying patients at risk of becoming disabled because of low back pain: the Vermont Rehabilitation Engineering Center predictive model. Spine 1991;16(6):605--7.

34. Volinn E, Mayer J, Diehr P, Van Koevering D, Connell FA, Loser JD. Small area analysis of surgery for low back pain. Spine 1992;17(5):575-81.

35. Haldeman S. Presidential address, North American Spine Society: failure of the pathology model to predict back pain. Spine 1990;15:718-24.

36. Waddell G. A new clinical model for the treatment of lowback pain. Spine 1987;12:632-44.

37. Coste J, Paolaggi J, Spira A. Classification of nonspecific low back pain: II clinical diversity of organic forms. Spine 1992;17(9): 1038-42.

38. Troup JDG, Slade PD. Fear avoidance and chronic musculoskeletal pain. Stress Med 1985;1:217-20.

39. Waddell G, Newton M, Henderson I, Somerville D, Main CJ. A fear-avoidance beliefs questionnaire (FABQ) and the role of fear-avoidance beliefs in chronic low back pain and disability. Pain 1993;52(2): 157-68.

40. Fletcher RH, Fletcher SW, Wagner EH. Clinical epidemiology: the essentials. 2nd ed. Baltimore, MD: Williams and Wilkins, 1988.

41. Calin A, Kaye B, Sternberg M, Antell B, Chan M. The prevalence and nature of back pain in an industrial complex - a questionnaire and radiographic and HLA analysis. Spine 1980;5(2):201-5.

42. Deyo RA, Rainville J, Kent DL. What can the history and physical examination tell us about low back pain? JAMA 1992;268(6):760-5

43. Hrudey WP. Overdiagnosis and overtreatment of low back pain: long-term effects. J Occup Rehabil 1991;1(4):303-12.

44. Deyo RA. Practice variations, treatment fads, rising disability: do we need a new clinical research paradigm? Spine $1993 ; 18(15): 2153-62$.
45. Frymoyer JW. An international challenge to the diagnosis and treatment of disorders of the lumbar spine. Spine 1993;18(15):2147-52.

46. Waddell G, Main CJ, Morris EW, DiPaola M, Gray ICM. Chronic low-back pain, psychologic distress, and illness behavior. Spine 1984;9(2):209-13.

47. Hayes B, Solyom CAE, Wing PC, Berkowitz J. Use of psychometric measures and nonorganic signs testing in detecting nomogenic disorders in low back pain patients. Spine $1993 ; 18(10): 1254-62$.

48. Matheson LN. Symptom magnification syndrome. In: Isserhagen SJ, editor. Work injury: management and prevention. New York, NY: Aspen Publishing, 1988.

49. Phillips HC, Grant L, Berkowitz J. The prevention of chronic pain and disability: a preliminary investigation. Behav Res Ther $1991 ; 29: 443-50$.

50. Crook JM. A longitudinal epidemiological study of injured workers: prognostic indicators of work disability [dissertation]. Toronto: Institute of Medical Sciences, University of Toronto, 1994.

51. Hadler N. Disabling back ache in France, Switzerland and The Netherlands: contrasting sociopolitical constraints on clinical judgement. J Occup Med 1989;31:823-31.

52. Bach $\mathrm{S}$, Noreng MF, Tjellden NU. Phantom limb pain in amputees during the first 12 months following limb amputation, after preoperative lumbar epidural blockade. Pain 1988;33:297-301

53. McQuay HJ, Dickenson AH. Implications of nervous system plasticity for pain management. Anaesthesia 1990;45(2): $101-2$.

54. Liang MH, Katz JN. Clinical evaluation of patients with a suspected spine problem. In: Frymoyer JW, editor. The adult spine: principles and practice. New York, NY: Raven Press, 1991:223-39.

55. Katz J, Vaccarino AL, Coderre TJ, Melzack R. Injury prior to neurectomy alters the pattern of autotomy in rats: behavioural evidence of central neural plasticity. Anaesthesiology $1991 ; 75: 876-83$

56. Dantzer R, Kelley KW. Stress and community: an integrated view of relationships between the brain and the immune system. Life Sci 1989;44:1995-2008.

57. Saplosky RM. Stress in the wild. Sci Am 1990;262:116-23.

58. Bennett RM, Clark SR, Campbell SM, Burckhardt CS. Patients with low levels of somatomedin can the fibromyalgia syndrome: a possible link between sleep and muscle pain. Arthritis Rheumatol 1993;36(9):5220.

59. Griep EN, Boersma JW, de Kloet ER. Altered reactivity of the hypothalamic pituitary — adrenal axis in the primary fibromyalgia syndrome. J Musculoskeletal Pain 1993;1: $217-22$

60. Russell IJ, Vipraio GA, Lopez YM. Serum serotonin in fibromyalgia syndrome, rheumatoid arthritis, osteoarthritis and healthy normal controls. Arthritis Rheumatol 1993;36(9): \$223.

61. Russell IJ, Vipraio GA, Acworth I. Abnormalities in the central nervous system (CNS) metabolism of tryptophan (TRY) to 3-hyroxykynurenine [OHKY] in fibromyalgia syndrome [FS]. Arthritis Rheumatol 1993;36(9):S222.

62. Russell IJ, Orr MD, Vipraio GA, Albankock D, Michalek JE MacKillip F, et al. Cerebrospinal fluid substance $P$ is elevated in fibromyalgia syndrome. Arthritis Rheumatol 1993; 36(10): $\mathrm{S} 223$

63. Feuerstein M, Sult S, Houle M. Environmental stressors and chronic low back pain: life events, family and work environ- 
ment. Pain 1985;22(3):295-307.

64. Fenerstein M, Papciak A, Hoon P. Bio-behavioural mechanisms of chronic low back pain. Clin Psychol Rev 1987; $7: 243-73$.

65. Feuerstein M, Thebarge RW. Perceptions of disability and occupational stress as discriminators of work disability in patients with chronic pain. J Occup Rehabil 1991;1:13595.

66. Niemeyer LO. Social labelling, stereotyping and observer bias in Workers' Compensation: the impact of provider patient intervention on outcome. J Occup Rehabil 1991; 1(4):251-9.

67. McCracken CM, Cross RT, Sorg PJ, Edmond TA. Prediction of pain in patients with chronic low back pain: effects of inadequate protection and pain-related anxiety. Behav Res Ther 1993;31(7):647—52.

68. Berkowitz M. Returning injured workers to employment: an international perspective. Geneva: International Labor Organization, 1990.

69. Canadian Auto Workers Union (CAW). Ergonomics in the work environment: a manual for workers. North York, Ontario: CAW, Health and Safety Communications Department, 1993.

70. Sackett DL. Bias in analytic research. J Chronic Dis 1979;32:51-63.

71. Frank JW. Occult blood screening for colorectal carcinoma: 1. the benefits. Am J Prev Med 1985;1(3):3-9.

72. Gyntelberg F. One year incidence of low back pain among male residents of Copenhagen aged 40 -59. Dan Med Bull 1974;21:30-36.

73. Frymoyer JW, Pope MH, Clements JH, Wilder DG, MacPherson B, Ashikaga T. Risk factors in low-back pain. J Bone Joint Surg 1983;65A(2):213-8.

74. Deyo RA, Tsui-Wu YJ. Functional disability due to back pain: a population- based study indicating the importance of socioeconomic factors. Arthritis Rheumatol 1987;30(11): $1247-53$

75. Jette $\mathrm{AM}$. The functional status index: reliability and validity of a self-report functional disability measure. J Rheumatol 1987;14 suppl 15:15-9.

76. Deyo RA, Diehl AK. Psychosocial predictors of disability in patients with low back pain. J Rheumatol 1988;15(10): 1557-64.

77. Riihimäki $H$, Tola $S$, Videman $T$, Hanninen K. Low-back pain and occupation: a cross-sectional questionnaire study of men in machine operating, dynamic physical work, and sedentary work. Spine 1989; 14(2):204-9.

78. Hogg-Johnson S, Frank JW, Rael E. Prognostic risk factor models for low back pain: why they have failed and a new hypothesis. Toronto: Institute for Work and Health, 1994. Working paper no 19.

79. Heliövaara $M$, Mäkelä $P$, Knekt P. Determinants of sciatica and low-back pain. Spine 1991;6:608-14.

80. Leavitt $F$. The physical exertion factor in compensable work injuries: a hidden flaw in previous research. Spine 1992; 17(3):307-10.

81. Cheadle A, Franklin G, Wolfhagen C, Savarino J, Liu PY, Salley $\mathrm{C}$ et al. Factors influencing the duration of workrelated disability: a population-based study of Washington State Workers' Compensation. Am J Public Health 1994; 84(2): 190-6

82. Bombardier C, Kerr MS, Shannon HS, Frank JW. A guide to interpreting epidemiologic studies on the etiology of back pain. Spine 1994;19(18S):2047—56.
83. Biering-Sorensen $\mathrm{F}$, Thomsen CE, Hilden J. Risk indicators for low back trouble. Scand J Rehabil Med 1989;21:151 -7.

84. Troup JDG, Foreman TK, Baxter CE, Brown D. The perception of back pain and the role of psychophysical tests of lifting capacity. Spine 1987;12(7):645-57.

85. Frymoyer JW, Cats-Baril W. Predictors of low back pain disability. Clin Orthop Rel Res 1987;211:89-98.

86. Burton AK, Tillotson KM. Prediction of the clinical course of low-back trouble using multi-variable models. Spine 1991: $16(1): 7-14$.

87. Vingård E, Hogstedt C, Alfredsson L, Hagberg M, Kilbom $\AA$, Németh G, et al. MUSIC-Norrtäle study - an ongoing epidemiological study on risk factors for low-back and neckshoulder disorders [abstract]. In: Tenth international symposium epidemiology in occupational health, Villa Erba, Como, Italy, September 20-23, 1994:161.

88. Kerr MS, Shannon HS, Frank JW, Norman RWK, Wells RP. Design of a case- control study for reported occupational low-back pain [abstract]. In: New pathways in epidemiology - International Epidemiological Association, September 26-29, 1993;142. Sydney, Australia.

89. Rothman KJ. Modern epidemiology. Toronto: Little, Brown and Company, 1986.

90. McKeown-Eyssen GE, Thomas DC. Sample size determination in case-control studies: the influence of the distribution of exposure. J Chronic Dis 1985;38(7):559-68.

91. Burdorf A. Exposure assessment of risk factors for disorders of the back in occupational epidemiology. Scand J Work Environ Health 1992;18:1-9.

92. Marras WS, Lavender SA, Leurgans SE, Rajulu SL, Allread WG, Fathallah FA, et al. The role of dynamic three-dimensional trunk motion in occupationally related low back disorders. Spine 1993;18(5):617-28.

93. Wiktorin C, Karlqvist L, Winkel J, Stockholm MUSIC I Study Group. Validity of self-reported exposures to work postures and manual materials handling. Scand J Work Environ Health 1993;19:208-14.

94. Phillips AN, Davey Smith G. Bias in relative odds estimation owing to imprecise measurement of correlated exposures. Stat Med 1992;11(7):953-61.

95. Bennett RM. Fibromyalgia. JAMA 1987;257(20):2802-3.

96. Frymoyer JW, Rosen JC, Clements J, Pope MH. Psychologic factors in low-back- pain disability. Clin Orthop 1985;195: $178-84$.

97. Härkapää K, Järvikoski A, Mellin G, Hurri H, Luoma J. Health locus of control beliefs and psychological distress as predictors for treatment outcome in low-back pain patients: results of a 3-month follow-up of a controlled intervention study. Pain 1991:46(1):35-41.

98. Dambrosia JM, Ellenberg JH. Statistical considerations for a medical data base. Biometrics 1980;36:323-32.

99. Woodbury MA, Clive J. Continuous and discrete global models of disease. Math Modeling 1986;1-18.

100. Summers JD, Rapoff MA, Varghese G, Porter K, Palmer RE. Psychosocial factors in chronic spinal cord injury pain. Pain 1991;47:183-9.

101. Marmot M. Socioeconomic determinants of coronary heart disease mortality. Int J Epidemiol 1989;18(3) Suppl 1:S196-S202.

102. Davey Smith G, Shipley M, Rose G. Magnitude and causes of socioeconomic differentials in mortality: further evidence from the Whitehall Study. J Epidemiol Community Health 1990;44:265-70.

103. Gyntelberg F, Suadicani P, Hein HO. Psychosocial work 
loads, social inequalities and risk of ischaemic heart disease - a prospective study in the Copenhagen Male Study [abstract]. In: The Danish Labor Inspection. International conference on work and health, February 22-25. Copenhagen: The Danish Labor Inspection, 1993:120.

104. Orth-Gomer K, Rosingren A, Wilhelmsen L. Lack of social support and incidence of coronary heart disease in middleaged Swedish men. Psychosom Med 1993;55:37-43.

105. Liang K-Y, Zeger SL. Longitudinal data analysis for discrete and continuous outcomes. Biometrics 1986;42:121-30.

106. Efron B, Tibshirani R. Statistical data analysis in the computer age. Science 1991;253:390—5.

107. Mustard JF, Frank JW. The determinants of health. Toronto: Canadian Institute for Advanced Research (CTAR), 1991. CIAR Population health program - publication no 5.

108. Evans RG, Barer ML, Marmor TR, editors. Why are some people healthy and others not? Hawthorne NY: Aldene de Gruyter, 1994.

109. Holman HR. Qualitative inquiry in medical research. J Clin Epidemiol 1993;46(1):29-36.

110. Spangfort, E. Disc surgery. In: Wall PD, Melzack R, editors. Textbook of pain. New York, NY: Churchill Livingstone,
1989:795-802.

111. Tarasuk V, Eakin JM. Social dimensions of the experience of work-related back problems. Toronto: Institute for Work and Health, 1993. Working paper no 6.

112. Tarasuk V, Eakin JM. "Back problems are for life": perceived vulnerability and its implications for chronic disability. J Occup Rehabil 1994;4(1):55-64.

113. Yelin E. Displaced concern: the social context of the workdisability problem. Milbank Q 1989;67 suppl 2, pt 1:11465.

114. McKinlay JB. The promotion of health through planned sociopolitical change: challenges for research and policy. Soc Sci Med 1993;36(2):109-17.

115. Kuhn T. The structure of scientific revolutions. Chicago, IL: University of Chicago Press, 1970.

116. Tesh S.N. Hidden arguments: political ideology and disease prevention policy. New Brunswick, NJ: Rutgers University Press, 1988.

Received for publication: 28 September 1994 